\title{
An Empirical Analysis on Why People Run Away from In-Feed Ads under Manufacturing Industry Innovation
}

\author{
Xiaobo Tao,Ziniu Jin* \\ North China University of Technology, Beijing, China \\ * Corresponding Author
}

\begin{abstract}
Thanks to the innovation in manufacturing industry, the rapid development ofdigital technologies such as mobile Internet and social media enables the appearance of up-to-date intelligent marketing methods. As one of them, In-Feed advertising becoming a fashionable approach due to its precise positioning and growing market share, problems such as loss of privacy and lack of trust arise which promote the avoidance behavior of consumer. Based on these facts, our study designs three experiments to explore the mechanism between the In-Feed advertising and the avoidance behavior of consumer. Furthermore, in order to give instructions on enhancing the communication effect of In-Feed ads, we tries to clarify the boundary conditions of consumers processing ads information. Experiment 1 examines the moderating effects of ad reviews between perceived relevance, threat appraisal and coping appraisal; Experiments 2 and 3 respectively examine the moderating effects of the connection strength and interaction frequency between consumers and ad-likers between the above variables. These three experimental results provide theoretical support and practical guidance for intelligent digital marketing and advertising.
\end{abstract}

Keywords:Manufacturing industry,Wechat Moments In-Feed advertising, Ad avoidance behavior, Protection Motivation Theory

\section{Introduction}

In-Feed advertising is one of the most effective forms of online advertising in the social media environment [1]. It can achieve precise push based on consumers' online behavior data and generate a highly personalized propagation effect. Since it was first launched by Facebook, this new advertising format has been widely used by more and more companies on social media platforms such as Twitter, WeChat, Weibo, and Toutiao. However, as privacy leaks emerging, consumers' avoidance of In-Feed ads becomes more and more notable. According to an evaluation report of WeChat users' response to In-Feed ads from IiMedia Research, only 5.2\% of the users from the surveyed group are willing to accept WeChatIn-Feed ads. Further analysis found that, while presenting a highly personalized propagation effect, In-Feed ads is inseparable from tracking, collecting and calculating of consumer online behavior data.

Reviewing the existing researches, it could be found that the academic circles have paid less attention to the avoidance behavior of In-Feed ads. Even in a small amount of literature involving advertising avoidance behavior $[2,3]$, few of them researches from the perspective of protection motivation theory. Up to now, protection motivation theory has been widely used in the fields of user health[4,5], Internet implementation[6-8], and organizational security[9-11]. Related researches have deeply explored the cognitive evaluation process of individuals facing various threat factors. In the context of privacy leaks, consumers will also conduct cognitive evaluations of the threats in front of them. Therefore, the theory of protection motivation has important guiding significance for studying the influence mechanism of In-Feed ads avoidance behavior in this situation.

Based on the above context, although In-Feed ads has vast range of prospects, the problem of privacy leakage occurs during the implementation process, which resulted in greater sensitivity of consumers to the threat factors from browsing In-Feed ads, and will eventually affect their willingness of avoidance behavior. Therefore, our study will initially construct a theoretical model of In-Feed ads avoidance behavior based on consumers' perception of and response to the threat of privacy leakage, and explore how consumers' social attributes affect ISSN: 0010-8189

(C) CONVERTER 2020

www.converter-magazine.info 
their process of evaluating and responsing to threats in the context of WeChat Moments advertising. By doing this, we want to figure out the way to reduce advertising avoidance behavior in the light of its general trend, make better use of In-Feed ads, and thus drive the development of the real economy more effectively.

\section{II.Theoretical Background and Research Hypotheses}

\subsection{The impact of the perceived relevance of In-Feed ads on ad avoidance behavior}

With the rise of the digital economy, intellectualization and platformization have enabled barrier-free, high-speed, and effective information circulation and sharing, making In-Feedadvertisments demonstrates two major advantages: First, it can accurately achieve personalized push of advertising information based on user personal and platform data. The second is that it can trigger users to actively participate in advertising interaction with social attributes based on social context [12]. As a new marketing pattern, users have become a more critical sector in the entire business value chain. Thus, it is significant for improving the marketing efficacy to examining the user's perception of advertising. Perceived Relevance was first advanced by [13], they define it as the extend to which individuals perceive objective things to be self-correlated, or the degree to which it is useful for achieving personal goals or values [13]. In this study, we consider the user's perceived relevance to the Moments In-Feed ads as the degree to which the advertisement information is related to individual's own needs, interests, or preferences, or the advertisement information is useful for individual to search for related products and strengthen participative interaction. In a research on personalized and precise advertising, Kim \& Huh (2017) [14]and Zhu \& Chang (2016)[15] found that consumers' perceived relevance of advertising has a positive impact on their advertising attitudes and advertising reaction.

Other researches focused on user's avoidance behavior of advertising. Since entering the 21 st centry, scholars from home and aboard classified avoidance behavior of advertising into three types: cognitive avoidance, emotional avoidance, behavioral avoidance [16,17]. With the rise of Internet technology, advertising avoidance no longer takes TV advertising as the main research object, but integrates multiple media in addition. The existing literatures mainly focus on the network advertising avoidance model, the limited attention theory [18], the persuasive knowledge model [19] and many other theoretical perspectives to analyze the mechanism of consumer avoidance behavior to In-Feed ads. These studies mostly focused on the positive (negative) perceptual cognitive state of consumers caused by external factors such as advertising content and audience psychology, thereby weakening (enhancing) consumers' tendency to adopt advertising avoidance behavior. Their main logic is developing analysis from possible threats that In-Feed ads may bring about to real life, but ignoring the precision and sociality of In-Feed ads push produced by big data, cloud computing,etc. As merchants and platforms pay more attention to accurate targeted advertising, it becomes more important to combine consumers' perception of advertising push in the new era to explore how consumers' cognitive decision-making process leads to consumers' final avoidance behavior from a systematic perspective. Therefore, our study believes that consumers' cognitive evaluation of the relevance and fit of the advertising content will affect their behavioral intentions of advertisment avoidance behavior when they are exposed to the Wechat Moments In-Feed ads. Moments ads can provide more personalized and accurate information pushes for different target individuals based on the track data of user online behavior. When users perceive that the advertising information is related to their own interests and preferences, or can meet their own shopping needs, that is, they have a high degree of perceived relevance of the advertisements, they tend to show more positive advertising evaluations. Therefore, we propose the following assumptions:

H1: The higher the consumer's perceived relevance to the Moments In-Feed ads, the weaker the avoidance intention of the advertisement.

\subsection{The mediating effect of threat appraisal and coping appraisal}

The motivation theory was put forward by Rogers in 1975 [20]. The theory pointed out that individuals will respond in a favorable or unfavorable way when facing certain risk factors in the internal and external environment $[21,22]$. The cognitive response process of individuals coping with external risk factors includes threat appraisal 
and coping appraisal,these two types of appraisal work together and results in protection motivation, which in turn forms different coping patterns for individuals in threatening situations. The protection motivation theory provides an mechanism explanation for clarifying consumers' avoidance behaviors of In-Feed ads. Although existing studies have put forward many related factors that affect advertising avoidance behavior, it is not clear how consumers evaluate these factors and what impact these factors have on consumers' cognitive decision-making process. In view of the precise push of information and privacy data leakage possibilities of the Moments In-Feed ads, the advertisement avoidance behavior should be the final product of consumers after judge and weigh. In this point, merely considering the consumer's perception of the advertisement content cannot fully explain the internal logic and induction mechanism of advertising avoidance behavior. Therefore, our study introduces threat appraisal and coping appraisal as the mediation variables of avoidance behavior in Moments ads, aiming to further explores the internal process of consumers in weighing the usefulness and threat of Moments ads.

\subsubsection{The impact of perceived relevance on threat appraisal and coping appraisal}

Baek and Morimoto (2012) [23] revealed in their research that customized advertising information that fits the preferences or tastes of each individual consumer will inevitably increase consumers' attention to their personal privacy information. Similarly, as realizing accurate and personalized push to consumers, the Moments In-Feed ads are making consumers aware of the leakage and illicit exploitation of their personal privacy data. Based on the theory of protection motivation, first of all, when facing a certain threatening situation, consumers will go through two processes of threat appraisal and coping appraisal for the protection of their own interests before taking appropriate protective actions. The comparison of threats and benefits and the weighing process of efficacy and cost are the key to solving the unbalance existence of information accuracy and privacy violations from Friend Moments ads. With reference to the theoretical model of Floyd, Prentice-Dunn \& Rogers (2000)[24], our study proposes that consumers' threat appraisal of Moments ads is the result of a comprehensive weighing judgment on the possibility of advertising infringing on personal privacy and the severity of the consequences. That is, threat appraisal $=$ (perceived susceptibility + perceived severity $)$; Consumers' coping appraisal to Moments ads is the result of the comprehensive comparison of the degree to which they avoid advertisements to protect personal privacy, their ability to take protective measures, and the cost of avoiding behavior, that is coping evaluation = (reaction efficacy + self efficacy-response cost). We believes that the increase in perceived relevance will promote the susceptibility and severity of privacy violations that consumers can perceive. With the maturity of technology and the improvement of the operability of accurate delivery, consumers become more concerned about the possibilities of personal data leakage and privacy violation, which leads to a higher degree of threat appraisal on the severity of consequences. Based on analysis above, we propose the assumption that:

H2: The higher the consumer's perceived relevance to the Moments In-Feed ads, the higher the threat appraisal of the advertisement.

On the other hand, based on the calculation function of coping appraisal, it can be seen that with the improvement of the perceived relevance of the Moments In-Feed ads, consumers will pay more attention to the satisfaction of the advertisement information for their own needs. At this time, if countermeasures were taken to cope with the threat of infringement of privacy, the reaction cost would greatly increase, which leads to lower degree of coping appraisal. Therefore, we proposes the following assumption:

H3: The higher the degree of consumer's perceived relevance to the Moments In-Feed ads, the lower the degree of coping appraisal to the advertisement.

\subsubsection{The impact of perceived relevance on threat appraisal and coping appraisal}

According to the explanation of the protection motivation theory, both threat appraisal and coping appraisal will affect the change of the individual's protection motivation and behavior intention [25].Once the individual truly recognizes the threat, he will take corresponding actions, that is, enter the process of coping appraisal. Regarding users' privacy and security of social networking sites, Mohamed (2012)[26] believe that individuals' sense of efficacy in responding to threats such as personal privacy leaks in the process of participating in social networks will enhance their willingness to protect personal privacy information. Lee \& Larsen (2009)[27]found in their research that when individuals believe that they need too much time, energy, and moneyto change their behavior 
habits, they are more wait-and-see and hesitant to adopt protective behaviors. In summary, when individual's perception of efficacy in the process of responding to threats is higher than the cost, that is, when individual's coping appraisalto which they respond to or avoiding threats are higher, his willingness to take protective behaviors are much more stronger. Our study believes that when processing threat appraisal of Moments ads, if consumers perceive high severity and susceptibility of personal privacy infringements that may be caused by participating in Moments ads, which means a higher level of threat appraisal of In-Feed ads, then they will demonstratestrong willingness to take protective behaviors to avoid Moments ads. Based on analysis above, we propose the assumption that:

H4: The higher the threat appraisal of consumers participating in Moments ads, the stronger their intention to avoid ads.

Similarly, our study believes that if consumers perceive that the response efficacy and self-efficacy of avoiding Moments ads are higher than the cost, when their appraisal of ability to respond to Moments advertising threats are high, they will take protection behavior, and will have strong willingness to avoid Moments ads. Therefore, we propose the following assumption:

H5: The higher the coping appraisalof the threat of Moments ads, the stronger the consumers' willingness to avoid advertising.

Based on the above assumptions, our study believes that if consumers perceive high relevance of Moments ads, they will enhance their threat appraisal of advertising infringing on personal privacy and weaken the coping appraisalof coping with threats in order to evade the impacts of Moments ads on their behavioral intentions. Therefore, we propose to the assumption that:

H6a: Consumers' threat appraisal of participating in Moments ads mediating the impact of perceived relevance on ad avoidance intentions.

H6b: Consumers' respond appraisal of coping with threats of Moments ads mediating the impact of perceived relevance on ad avoidance intentions.

\subsection{The moderating effect of ad reviews, intensity and frequency of interaction}

The concept of advertising reviews comes from online reviews. Ho-Dac, Stephen \& William (2013)[28] pointed out that online reviews refer to consumers posting positive or negative opinions about products on the website.In this study, we would like to define advertising reviewsas: when consumers receive Moments advertising information, they also obtain evaluation information such as likes and messages left by their WeChat friends under the advertisement. A research conducted by Xu and Yang (2016)[29] on the reception effect of Moments ads also shows that variables such as WeChat friends' likes and positive comments on ads have a very significant impact on users' participation ofIn-Feed ads. Our study believes that in a common situation where user friends can comment and interact with each other in Moments ads, the more likes and comments, the stronger and easier the consumer can get from the "social identity" from the advertisement, and get emotional satisfaction such as social belonging [30,31]. The greater the number of ad reviews, the lower the consumer's threat appraisal of the ad. Therefore, we propose the assumption:

H7a:Advertising reviews mediates the relationship between perceived relevance and threat appraisal. When consumers' WeChat friends have a large number of likes and comments on Moments ads, the positive impact of perceived relevance on threat appraisal will be weakened.

Similarly, the increase in advertising review information will make the value of advertising more prominent in consumers' minds, and the efficacy of avoiding advertising to protect personal privacy will be significantly weakened. At the same time, the response cost of avoiding advertising will also make consumers harder to accept. That is to say, the more the number of ad reviews in Moments ads, the lower the degree of consumer coping appraisal. Then we propose to the assumption that: 
H7b:Advertising reviews mediates the relationship between perceived relevance and coping appraisal. When consumers' WeChat friends have a large number of likes and comments on Moments ads, the negative impact of perceived relevance on coping appraisal will increase.

Connection strength refers to the strength or effectiveness of interpersonal relationships in the context of personal social networks. As a construct with multi-dimensional attributes, the strength of connection can be measured and evaluated through some basic indicators[32]. Our study believes that the strength of connection is a relationship state in which consumers who comment on advertisements and their friends have social connections based on certain common attributes, and then resonate and rely on each other in terms of intimacy and emotional strength. Studies have shown that the strength of connection between users plays an important role in influencing users' cognition and attitude [33]. The interactive behaviors between users with strong connections in social networks can enable similar behaviors, concepts, and emotions to be transmitted between friends [34], indirectly promote the interaction between users and brands, thereby enhancing the effect of advertising. Carr \& Foreman (2016)[35] pointed out that consumers' attitudes are more likely to be consistent with friends who are strongly connected, and their behavior intentions are also easily affected by the attitude of strongly connected friends. Therefore, our study believes that when the strength of the relationship between the publisher of an advertisement review and the consumer is high, the trust in friends and the need for social interaction will finally weakens the threat appraisal of advertising. The likes, comments and other behaviors of strong connections with friends also indirectly convey their recent behavioral status and interest concerns, so that consumers can obtain more interest and social satisfaction from participating in advertising while obtaining advertising information, thereby further reducing consumers' sense of efficacy in avoiding advertisements and protecting personal privacy, and weakening their coping appraisal to advertisements. Based on analysis above, weproposes the following assumptions:

H8a: The strength of the connection moderates the relationship between perceived relevance and threat appraisal. When the strength of the connection between the publisher of the ad review and the consumer is high, the positive effect of perceived relevance on threat appraisal will be weakened.

H8b: The strength of connection moderates the relationship between perceived relevance and coping appraisal. When the strength of the connection between the publisher of the ad review and the consumer is high, the negative effect of the perceived relevance on the coping appraisal will increase.

Ha \& James (1998)[36] believes that interaction refers to the extent to which the communicator and the audience respond to each other or are willing to facilitate each other's communication needs. We believes in our study that the interaction between consumers who comment on advertisements and their friends is the relation state of mutual connection, mutual response, and mutual influence between the two parties based on certain specific events within a certain period of time. The social interaction between consumers and publishers of In-Feed ads reviews based on certain events will also affect their perception of advertising. Studies have shown that users and their friends communicate with each other on social platforms because of the need to improve group identity [37]. Therefore, we believes that in the context of Moments In-Feed ads, those WeChat friends who have maintained a high frequency of interaction with consumers in short-term provide a basic trust endorsement for consumers to perceive advertisements. Consumers will reduce their attention to the advertising elementsin information content based on their group identity, promotion of communication and other needs. Instead, they will regard it more as a media tool to enhance emotional communication between each other, and therefore will greatly reduce threat appraisal of personal privacyinfringement from advertisement. At the same time, the higher the frequency of social interaction between consumers and their friends, the higher their perception of the value of information and group identity conveyed by advertisements, this will not only weaken consumers' sense of efficacy in avoiding advertisements to protect personal privacy, but also increasing the response cost of avoiding advertisements which will finallyreduces consumers' coping appraisal. Based on analysis above, our study proposes following assumptions:

H9a: The frequency of interaction moderates the relationship between perceived relevance and threat appraisal. When the frequency of interaction between ad review publishers and consumers is high, the positive impact of perceived relevance on threat appraisal will be weakened. 
$H 9 b$ : Interaction frequency moderates the relationship between perceivedrelevance and coping appraisal. When the frequency of interaction between ad review publishers and consumers is high, the negative impact of perceived relevance on response appraisal will increase.

Based on the above theoretical foundation and hypothetical deduction, the research framework of our study is shown in Figure 1. The study included three experiments, and each experiment was conducted separately for different moderating variables. Among them, the purpose of Experiment 1 is to test the moderating effect of advertising reviews between perceived relevance, threat appraisal, and copingappraisal; Experiments 2 and 3 respectively test the moderating effect of connectionstrength and interaction frequency between consumers and ad-likers among the abovingvariables.

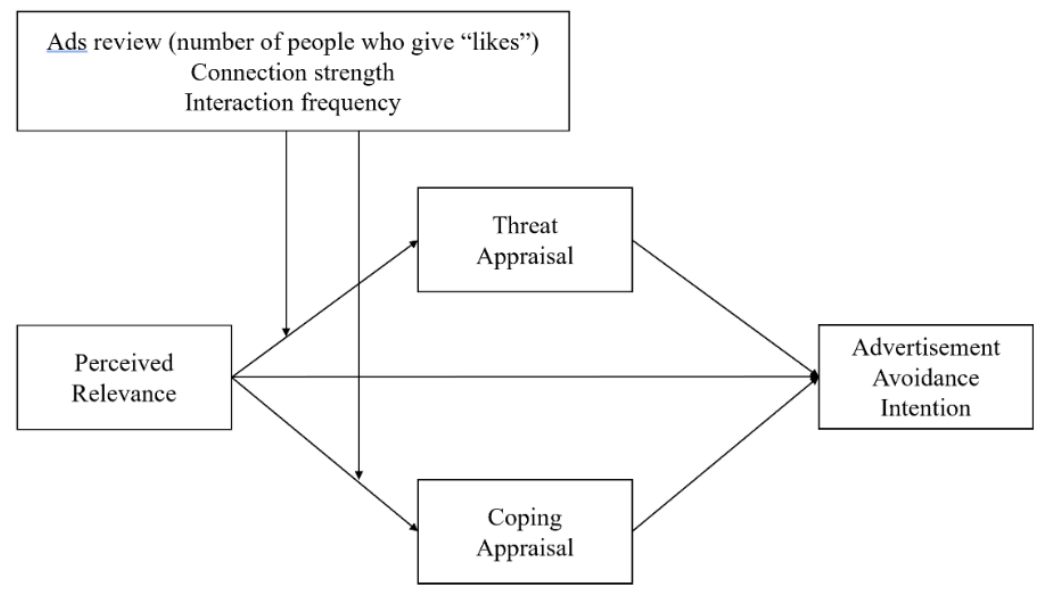

Figure 1. Research Framework

\section{III.Research Design}

\subsection{Experimental subjects and materials}

In this study, experimental subjects are college students who use Wechat with high frequency, and materials are Vivo mobile advertismentswhich appear frequently in Wechat Moments. We useexperimental method to collect quantitative data, following by testing the moderating effect of advertising review, connection strength and interaction frequency on advertising cognition appraisal, and conducting hypothesis test through structural equation model, Bootstrapping analysis and other methods. The experimental design refers to the research results of Zarouali, Poels\&Walrave (2018)[38], and creates a questionnaire to simulate the behavioral decisions of users when they see Vivo mobile phone ads in Moments.

\subsection{Variable measurement}

The variables designed in this study include perceived relevance, threat appraisal, coping appraisal and advertising avoidance intention. Among them, threat appraisal includes perceived susceptibility and perceived severity, and coping appraisal includes three variables: response efficacy, self-efficacyand response cost. These seven variables have been studied by a large number of scholars. This article draws on the existing mature scales, and combined with the actual situation of this research to make appropriate adaptations and adjustments to obtain the final scale. At the same time, in order to minimize the interference effects of specific experimental materials on the subjects in terms of brand preference, we chose three variables, brand recognition, brand familiarity and brand emotion as the control variables of this study. The four scales of perceived relevance, threat appraisal, coping appraisal, and advertising avoidance intention are shown in Tables 1,2,3 and 4.

Table1 Perceived Relevance Scale 
1. I think that Moments ad fit my personal interests, preferences and tastes

Perceived 2. I think that Moments ad is related to my current personal needs

relevance $\quad 3$. I think that Moments ad is worthy of my attention

Jung (2017) $)^{[42]}$;

Kim \& Huh

4. I think that Moments ad can impress me

$(2017)^{[14]}$

5. I think that Moments ad is customized for me

Table2 Threat Appraisal Scale

\begin{tabular}{|c|c|c|}
\hline Dimensions & Items & Sources \\
\hline \multirow{9}{*}{$\begin{array}{l}\text { Perceived } \\
\text { Susceptibility }\end{array}$} & $\begin{array}{l}\text { 1. I feel that clicking on "View Details","Learn More","Follow the Official } \\
\text { Account" or liking or commenting on the Moments ads will further lead to my } \\
\text { personal behavior data being tracked by ads providers. }\end{array}$ & \multirow{16}{*}{$\begin{array}{l}\operatorname{Dinev}(2004)^{[43]} \\
\text { Woon }(2005)^{[44]} \\
\text { Crossler }(2010)^{[45]}\end{array}$} \\
\hline & $\begin{array}{l}\text { 2. I feel that clicking on "View Details","Learn More","Follow Official } \\
\text { Account" or like or commenting on the Moments ads will cause my personal } \\
\text { data to be provided without my acknowledgement to unknown individuals or } \\
\text { companies }\end{array}$ & \\
\hline & 3. I feel that clicking on " View Details ", " Learn More ", " Follow the & \\
\hline & Official Account " or like or comment on the Moments ads will cause my & \\
\hline & personal data to be provided to government agencies & \\
\hline & 4. I feel that clicking on " View Details", " Learn More ", " Follow the & \\
\hline & $\begin{array}{l}\text { Official Account " or like or comment on the Moments ads will lead to the } \\
\text { abuse of my personal data by unknown companies without my }\end{array}$ & \\
\hline & acknowledgement & \\
\hline & $\begin{array}{l}\text { 5. I feel that clicking on "View Details"," Learn More ", " Follow the Official } \\
\text { Account " or like or comment on the Moments ads will expose my personal } \\
\text { privacy information to some malicious information security threats (Identity } \\
\text { theft, hacking, etc.) }\end{array}$ & \\
\hline \multirow{7}{*}{$\begin{array}{l}\text { Perceived } \\
\text { Severity }\end{array}$} & $\begin{array}{l}\text { 1. I think it's a serious problem for Moments ads to track my personal online } \\
\text { behavior }\end{array}$ & \\
\hline & 2. I think it is not safe for Moments ads to control my online behavior data & \\
\hline & $\begin{array}{l}\text { 3. I think the disclosure of personal online behavior data caused by Moments } \\
\text { ads is a serious problem }\end{array}$ & \\
\hline & 4. I think the disclosure of personal privacy information caused by Moments & \\
\hline & ads is a serious problem & \\
\hline & 5. I think it's a serious problem that personal online identities are stolen by & \\
\hline & Moments ads & \\
\hline
\end{tabular}

Table3 Coping Appraisal Scale

\begin{tabular}{|c|c|c|}
\hline Dimensions & Items & Sources \\
\hline $\begin{array}{l}\text { Response } \\
\text { efficacy }\end{array}$ & $\begin{array}{l}\text { 1. If I did not click "View Details","Learn More" or "Follow Official } \\
\text { Account" at the bottom of the Moments ads, I can protect my online } \\
\text { behavior data from further tracking } \\
\text { 2. If I do not like or comment on the Moments ads, I can protect my online } \\
\text { behavior data from further tracking } \\
\text { 3. If I click the "I am not interested" button, I can reduce the appearance of } \\
\text { such advertisements in my Moments } \\
\text { 4. If I avoid the Moments ads, I can better protect personal privacy } \\
\text { information security } \\
\text { 5. If I take some privacy protection measures while using WeChat, I can } \\
\text { better protect personal privacy information }\end{array}$ & $\begin{array}{l}\text { Crossler }(2010)^{[45]} \\
\operatorname{Marett}(2011)^{[46]}\end{array}$ \\
\hline Self-efficacy & 1. In the process of browsing WeChat Moments, I can easily avoid such & Woon $(2005)^{[44]}$ \\
\hline
\end{tabular}




\begin{tabular}{|c|c|c|}
\hline Dimensions & $\begin{array}{ll} & \text { Items } \\
\end{array}$ & Sources \\
\hline & $\begin{array}{l}\text { Moments ads } \\
\text { 2. If the Moments advertisement can meet my personality preferences or } \\
\text { current needs, I have the ability to control myself not to pay attention and } \\
\text { participate } \\
\text { 3. If the Moments ad has my friends' likes or comments, I have the ability to } \\
\text { control myself not to participate in the ad comment } \\
\text { 4. I can avoid the tracking of my personal online behavior history by the } \\
\text { Moments ads } \\
\text { 5. In the process of using WeChat, I can easily enable the privacy protection } \\
\text { function }\end{array}$ & $\begin{array}{l}\text { Larose }(2007)^{[47]} \text {; } \\
\text { Marett, }(2011)^{[46]}\end{array}$ \\
\hline Reaction cost & $\begin{array}{l}\text { 1. Avoiding the Moments ads will cause me to miss accurate advertising } \\
\text { information push } \\
\text { 2. Avoiding the Moments ads will cause me to miss the discount } \\
\text { information. } \\
\text { 3. Avoiding the Moments ads will prevent me from receiving some valuable } \\
\text { information from the official account } \\
\text { 4. Avoiding the Moments ads will prevent me from having funny } \\
\text { interactions with WeChat friends }\end{array}$ & Marett, $(2011)^{[46]}$ \\
\hline Variable & Items & sources \\
\hline $\begin{array}{c}\text { Ad avoidance } \\
\text { intention }\end{array}$ & $\begin{array}{l}\text { 1. I will intentionally ignore the Moments ads } \\
\text { 2. It would be better if there is no such kind of Moments ads } \\
\text { 3. I hate this kind of Moments ads } \\
\text { 4. I will avoid browsing the Moments ads in various ways } \\
\text { 5. I don't want to appear in the behavioral target list of the } \\
\text { Moments ads }\end{array}$ & $\begin{array}{l}\text { Kelly, Kerr } \\
(2010)^{[48]}\end{array}$ \\
\hline
\end{tabular}

\subsubsection{Questionnaire design and modification}

Based on the above scale, a questionnaire was designed to measure perceived relevance, threat appraisal, coping appraisal, and advertising avoidance intention. All of the question items use the Likert seven-level scale, and the index evaluation in the questionnaire decreases according to the value of the score, of which 1 means very disagree, 2 means basically disagree, 3 means disagree, 4 means unclear, 5 means slightly agree, 6 means basically agree, and 7 means strongly agree.

The questionnaire in this experiment is divided into three parts. The first part is a measurement questionnaire about perceived relevance, threat appraisal, coping appraisal and advertising avoidance intention. Participants in each group answer the corresponding questions after reading the description of the situation. The second part is the measurement questionnaire about the control variables in the experiment, which mainly includes brand familiarity, brand recognition and brand emotion. The third part is the demographic information of the questionnaire. The question design of the questionnaire all adopts the form of multiple choice and closed questions.

\subsubsection{Manipulation test of demographic factors and reliability and validity test of the scale}

Taking the avoidance intention of advertisement as the dependent variable, sereral effects are tested whether the influence of age and gender of the subjects are significant. According to the results ofvariance analysis, gender and age have no significant influence on their advertising avoidance intention $(\mathrm{p}>0.05)$, and demographic factors are successfully controlled.

In the test results for each latent variable reliability showed that the Cronbach's $\alpha$ of each construction are all above 0.8 (the Cronbach's $\alpha$ of self-efficacy, cost of the reaction are slightly less than 0.8 ), and the results of reliability test is good. Secondly, the standardized factor loading values of each construct are generally above 0.6 , the average 
variance extraction values (AVE) are generally greater than 0.5 (the AVE of self-efficacy, reaction cost is slightly less than 0.5), and the combined reliability values (CR) are allabove the minimum critical level of 0.70 , which indicates that each latent variable has good convergent validity, and the measurement items of each potential construct have a high degree of correlation and consistency, and they can better reflect the same potential traits measured by each. Finally, the square roots of each construct's AVE are greater than the correlation coefficient between itself and other constructs, indicating that the discriminant validity between the various latent variables in this study is good, there are significant differences between the variables.

\section{IV.Hypothesis test}

\subsection{Model path}

Our research uses Mplus7.0 to test the constructed theoretical model and hypothesis through structural equation model analysis. The results are shown in Table 5. The model fitting results showed that the CFI value was 0.998 , the TLI value was 0.988 , and the RMSEA value was 0.045 , indicating that the overall model fits well.

At the same time, in the inspection of the path relationship formed by different variables, the perceived correlation has a significant negative impact on the avoidance intention of advertisements $(\beta=-0.141, \mathrm{p}<0.05)$, hypothesis H1 is verified; the perceived correlation has a significant impact on threat assessment The positive influence of $\beta=$ $0.508, \mathrm{p}<0.001)$, the hypothesis $\mathrm{H} 2$ is verified; the perceptual correlation has a significant negative impact on the evaluation $(\beta=-0.552, \mathrm{p}<0.001)$, and the hypothesis H3 is also verified. Similarly, threat assessment $(\beta=0.423, \mathrm{p}$ $<0.001)$ and coping appraisal $(\beta=0.418, \mathrm{p}<0.001)$ both have a significant positive impact on advertising avoidance intentions. Hypotheses $\mathrm{H} 4$ and $\mathrm{H} 5$ have been verified.

Table 5 Test results of model path

\begin{tabular}{|c|c|c|c|c|}
\hline \\
\hline Model path & Estimate & S.E. & Est. / S.E. & Two-Tailed P Value \\
\hline Perceived releavance - Ads avoidance & $-0.141^{*}$ & 0.063 & -2.241 & 0.025 \\
\hline Perceived releavance - Threats appraisal & $0.508 * * *$ & 0.047 & 10.789 & 0.000 \\
\hline Perceived releavance - Coping appraisal & $-0.552 * * *$ & 0.072 & -7.721 & 0.000 \\
\hline Threats appraisal - Ads avoidance & $0.423 * * *$ & 0.068 & 6.237 & 0.000 \\
\hline Coping appraisal - Ads avoidance & $0.418 * * *$ & 0.068 & 6.172 & 0.000 \\
\hline
\end{tabular}

\subsection{Mediation effect}

Our study uses the Processprogram in SPSS24.0 software, and follows the mediation effect analysis steps proposed by Zhao, Lynch Jr\& Chen (2010)[39], and refers to the Bootstrap method proposed by Preacher \& Hayes (2004)[40] and Hayes (2013)[41]to carry out the mediation effect test, the sample size is 5000, and the 95\% confidence interval is set. The inspection results are shown in Table 6 . The results show that the mediating effect of threat appraisal and coping appraisal is not significant (LLCI=-0.142, ULCI=0.143), which 0 is included in the confidence interval; however, threat appraisal(LLCI=0.133, ULCI=0.302) and coping appraisal(LLCI=-0.313, ULCI=-0.115) manifest significant mediating effects separately, which means 0 is not included intheir confidence intervals, and the precise number of the mediating effect is 0.215 and -0.216 respectively. Therefore, it is confirmed that both H6a and H6b have been verified.

\begin{tabular}{ccccc} 
Table 6.The mediating effect between perceived relevance and ads avoidance \\
\hline Mediating variables & Effect & BootSE & BootLLCI & BootULCI \\
\hline Threat appraisal & -0.001 & 0.072 & -0.142 & 0.143 \\
Coping appraisal & 0.215 & 0.043 & 0.133 & 0.302 \\
Threat appraisal & 0.0513 & -0.115 \\
Coping appraisal & -0.216 & 0.050 & -0.313 \\
\hline
\end{tabular}

4.3 Experiment 1: Test of advertisement reviews

\subsubsection{Experimental design}

ISSN: 0010-8189

(C) CONVERTER 2020 
In this experiment, we mainly concentrated on how users' perceived relevance of advertisements has different influential paths and effects on their threat appraisal and coping appraisal when the number of likes on Moments ads is different. We firstly developed a single factor intergroup design in which the first scenerio has 1 likes (less likes) and the second sceneriohas 10 likes (more likes), and a control scenerio with 0 like.All participants were randomly divided into 3 groups and completed the experiments in each scenarioseperately. We used Vivo mobile advertisments as experiment material. Participants in each group filled out questionnaires on perceived relevance, threat appraisal, response appraisal, and advertisment avoidance intention after reading the description of the experimental scenario.

\subsubsection{Results}

First, we conducted the manipulation test. Among the 36 participants in experimental group 1, 34 people thought that the number of likes they saw under the Moments ads was too small, accounting for 94.45\%; Among the 36 participants in experimental group 2, 35 people thought the number of likes under the Moment ads is too large, accounting for $97.22 \%$. More than $90 \%$ of the participants in each group developed the expected judgments which means that they were consistent with the experiment scenarios.

Second, we conductedmoderation effect test. Wecentralized theperceivedrelevance, and develop the interaction terms by multiplied perceived relevance with the number of likes, connection strength, and interaction frequency, then the regression models for threat appraisal and coping appraisalweredeveloped in turn. By using the Process program in SPSS24.0 software,we selected Model 1 to perform a simple moderation effect test, the sample size was 5000 , and the $95 \%$ confidence interval was set. The results show that brand awareness has a significant positive effect on threat appraisal $(\beta=0.269, \mathrm{p}<0.001)$ and coping appraisal $(\beta=0.090, p<0.001)$, while the variables such as brand familiarity and brand sentiment did not manifest significant effects on consumers' cognitive appraisal. This shows that the introduction of brand awareness as a control variable into the regression model is conducive to obtaining more accurate results of perceived relevance and ad comments for threat appraisal and coping appraisal. After controlling the above-mentioned variables about advertising brands, wedraws the following conclusions: Perceived relevance has a significant positive impact on threat appraisal $(\beta=0.397$, $\mathrm{p}<0.001$ ), while the interaction term of perceiced relevance and the number of likes has a significant negative effect on threat appraisal $(\beta=-0.360, \mathrm{p}<0.001)$.

This result indicates that the number of likes plays a negative moderating effect between perceived relevance and threat appraisal,hypothesis H7a is verified; Similarly, the perceived relevance has a significant negative effect on coping appraisal $(\beta=-0.217, \mathrm{p}<0.001)$, and the interaction term of perceived relevance and the number of likes also has a significant negative effect on coping appraisal $(B=-0.187, p<0.001)$, the results verify the positive moderation effect of the number of likes on the coping appraisal, hypothesis $\mathrm{H} 7 \mathrm{~b}$ is verified.

\subsubsection{Discussion}

Experiment 1 verified that the assumptions $\mathrm{H} 1-\mathrm{H} 7$ are all valid. Among them, advertising reviewsmoderates the relationship between perceived relevance and threat appraisal. When the number of likes is large, the perceived relevance will weaken the positive impact of threat appraisal; Advertising reviews also moderates the relationship between perceived relevance and coping appraisal. When the number of likes is large, the negative impact on coping appraisal from perceived relevance will increase.

\subsection{Experiment 2: Test of connection strength}

\subsubsection{Experimental design}

Experiment 2 mainly focus on the influence path and effect of the user's perceived relevance of the advertisement on the threat appraisal and coping appraisal when the connection strength between the ad liker and ad vieweris changing. We developed a single factor between-group design that 2 groups were settled depending on the connection strength among which the person who gave likes in the first group is a newly added friend (weak connection strength) and that in the second group is an immediate family member (strong connection). Besides, 
there was a also a control group in which there was no one gave likes. The experimental materialswere Vivo mobile phone advertisments. Participants in each group filled out questionnaires on perceived relevance, threat appraisal, coping appraisal, and advertising avoidance intention after reading the description of the experimental scenario.

\subsubsection{Results}

First, we conducted a manipulation test on the connection strength. Among the 36 subjects in experimental group 1, 35 people thought that the connection strength between those who liked the Moments ads and themselves was weak, accounting for $97.22 \%$; among the 36 subjects in experimental group 2, 36 people believed that the people who likedthe Moments ads have a strong connection strength with themselves, accounting for $100 \%$. More than 95\% of the participants in each group developed the expected judgments which means that they were consistent with the experiment scenarios, which means that connection strength was sucessfully manipulated.

Second, we conducted hypothesis test. The results show that brand awareness had significant effect to threat appraisal $(\beta=-0.144, p<0.05)$, and brand emotion had significant effect to threat appraisal $(\beta=0.180, p<0.01)$, and coping appraisal $(\beta=-0.123, p<0.001)$. This result shows that it is meaningful to add the above-mentioned control variables to the regression model, and can obtain more accurate results of the impact of perceived relevance and connection strength on threat and coping appraisal. Therefore, after controlling the related variables, we made the following conclusions: Perceived relevance has a significant positive impact on threat appraisal $(\beta=0.333$, $\mathrm{p}<0.001$ ), but the interaction term of perceived relevance and connection strength has a significant negative effect on threat appraisal $(\beta=-0.155, \mathrm{p}<0.05)$.

This result indicates that the connection strength exerts a negative moderating effect between perceived relevance and threat appraisal. Hypothesis H8a has been verified; Similarly, the perceived relevance has a significant negative impact on coping appraisal $(\beta=-0.112, \mathrm{p}<0.001)$, and the interaction term of perceivedrelevance and connection strength also has a significant negative impact on coping appraisal. $(B=-0.439, p<0.001)$, the results verified the positive moderation effect of connection strength on coping appraisal, and hypothesis H8b was supported.

\subsubsection{Discussion}

Experiment 2 confirmed that hypothesis $\mathrm{H} 8$ was verified. Which means the connection strength will moderate the relationship between perceived relevance and threat appraisal. When the connection strength between the publisher of an ad review and the consumer is high, the positive impact of perceived relevance on threat appraisal will be weakened; The connection strength will also moderate the relationship between perceived relevance and coping appraisal. When the connection strength between the publisher of an ad review and the consumer is high, the negative impact of perceived relevance on coping appraisal will be enhanced.

\subsection{Experiment 3: Test of interaction frequency}

4.5.1 Experimental design

Experiment 3 mainly researches the influence path and effect of the user's perceived relevance on the threat appraisal and coping appraisal when the interaction frequency between the ad liker and the ad vieweris changing. We developed a single factor between-group design that 2 groups were settled depending on the interaction frequency among which the likers and users have 1-3 contacts within a month (low interaction frequency)in the first group and that in the second group have 6-10 contacts within a month. Besides, there was a also a control group in which there was no interaction. The experimental materialswere Vivo mobile phone advertisments. Participants in each group filled out questionnaires on perceived relevance, threat appraisal, coping appraisal, and advertising avoidance intention after reading the description of the experimental scenario.

\subsubsection{Results}


First of all, we conducted a manipulation test of the interaction frequency. Among the 36 subjects in experimental group 1, 32 people thought that the interaction frequency between Moments ad likers and themselves was low, accounting for $88.89 \%$; Among the 36 subjects in experimental group 2, 34 people thought the ad likers had a high interaction frequency with themselves, accounting for $94.44 \%$.Nearly $90 \%$ of the participants in each group developed the expected judgments which means that they were consistent with the experiment scenarios, which means that connection strength was sucessfully manipulated.

Then we conducted hypothesis test. Brand familiarity has a significant negative effect on coping appraisal ( $\beta=$ $-0.105, \mathrm{p}<0.001)$. After controlingthe variables such as brand familiarity, brand awareness, and brand emotion, we obtained the results that: the interaction term of brand familiarity and interaction frequency has no significant effect on threat appraisal ( $\beta=0.059, \mathrm{p}>0.05$; LLCI $=-0.041$, ULCI $=0.156)$; and the interaction term of perceived relevance and interaction frequency had no significant effect on coping appraisal either $(\beta=0.050, p>0.05$; LLCI=-0.021, ULCI=0.121). Therefore, H9A, H9b were not verified.

\subsubsection{Discussion}

Experiment 3 verified that the hypothesis H9 is not true. When the interaction frequency is high between ad reviewers and consumers, the positive effect from perceived relevance to threat appraisal and the negative effect from perceived relevance to coping appraisal are all not significant. First of all, the interaction frequency between consumers and the Moments ad likers has an impact on their evaluation and response to advertising threats, and they are susceptible to be interferedby the strength of the relationship between them, which affects the test results. That is to say, the two parties with high interaction frequency may only maintain a higher frequency of communication because of the need to complete a specific task, but have not produced a strong enough relationship in intimacy and emotional intensity. Secondly, the interaction frequency is only one of the dimensions of the interpersonal relationships, and other types of interpersonal interaction may also have an impact on the aforementioned moderation process. Finally, the unverified hypothesis of the moderation effect of interaction frequency may not come from the influence of the interpersonal relationship, but is interfered by consumers' perception of the Moments advertisement itself or the pre-emptive emotional tendency. Even if friends with high interaction frequency give "likes" to the advertisement, consumers may also strengthen their threat appraisal of the advertisement due to the negative perception and emotional tendency of the advertisement content, advertisement presentation form, and advertisement brand.

\section{Conclusion and outlook}

\subsection{Research conclusion}

Based on the existing research results, this article systematically analyzes the theoretical mechanism of advertising avoidance behavior under the trend of digitalization and informatization by comprehensively combing the influencing factors of consumer In-Feed ads avoidance behavior. Based on the element content and action path of the protection motivation theory, combining with the special research scenarios of WeChat Moments advertising, a model of the influence mechanism of WeChat Moments In-Feed ads avoidance behavior is proposed, which is basically supported by empirical analysis. The main findings of the research are: (1) Perceived relevance is an important factor influencing advertising avoidance behavior, and it has a significant negative impact on consumers' advertising avoidance intentions; (2) Threat appraisal and coping appraisalare two important mediation paths between perceived relevance and advertisement avoidance intentions, threat appraisal and coping appraisal will present mediation effects in opposite directions; (3) Advertising comments and connection strength constitute the boundary conditions that affect consumers' advertising cognitive appraisal process. In general, as the number of ad comments becomes greater, and as the connection strength between likers and consumers becomes stronger, consumers' threats appraisal will become weaker, and at the same time their coping appraisalwill be enhanced.

\subsection{Theoretical contributions}

Guided by the protection motivation theory, our research puts forward a model of consumers' influence on the avoidance behavior of WeChat Moments In-Feed ads, and is basically supported by empirical analysis. The 
theoretical contributions of this research are as follows: (1) This research introduces the protection motivation theory into the research field of consumer advertising avoidance behavior, and proposes a new theoretical perspective for understanding the phenomenon of advertising avoidance, which enriches the research on the mechanism of consumer advertising avoidance behavior ; (2) This research system reveals how consumers can recognize and respond to the usefulness and threat of advertising when they are faced with the contradictory situation of accurate information recommendation in Moments advertising and easy leakage of personal privacy, which opens up the theory "black box" of consumers' choice to avoid advertising ; (3) Taking into account of the unique social attributes given to consumers by Moments In-Feed ads, this study explores the boundary conditions that affect the formation mechanism of advertising avoidance, and further enriches the theory of protection motivation

\subsection{Practical significance}

The influence mechanism model of WeChat Moments In-Feed ads avoidance behavior discovered in this study provides theoretical reference and practical guidance for intelligent digital marketing and advertising: (1) Advertisers should put more accurate advertising information for more focused target groups to improve the matching degree between advertising audience and advertising itself. (2) The Moments ads put by advertisers should further improve the richness of their advertising content, the novelty of advertising forms, the controllability of advertising presentation time, and the sense of participation and initiative of users in the process of browsing advertisements. (3) Advertisers should make full use of the social attributes of the WeChat platform when placing Moments ads, and enhance the interpersonal interaction between advertising audiences and their WeChat friends, increase consumer participation in advertising, and achieve secondary advertising.

\subsection{Research limitations and future prospects}

Based on the theoretical framework of protection motivation theory, this research puts forward a more complete model of the mechanism of consumers avoiding Moments ads, and is partially supported by empirical research. However, there are still the following shortcomings: (1) In this paper, perceived relevance is used as the main explanatory variable to influence consumers' avoidance behavior in advertising, but the relevant factors of advertising attributes such as advertising content, advertising form, advertising presentation time, advertising brand and so on are not fully considered, so the research model proposed in this paper still has room for further improvement. (2) In order to explore the influence of the relationship state between consumers and their friends who gave likes on their advertising cognitive appraisal, whether it will be interfered by variables such as advertising content and consumers' brand attitude remains to be further studied. (3) The connection strength and the interaction frequency are the two dimensions to measure the relationship state between individuals, but in the process of adjusting consumers' cognitive appraisal of advertising, whether there is a cross effect between the two and whether they promote or weaken each other needs to be further clarified. Future scholars can sort out and systematically classify the relevant factors of the attributes of Moments ads in more detail, and explore how different advertising content, advertising forms and other factors affect consumers' advertising avoidance intentions, so as to get more practical significant research results. At the same time, the experimental scenario design of this research can be further improved, and by accurately controlling the factors related to the advertising attributes, a more reliable moderation effect should be exerted in the individual relationship state.

\section{Acknowledgement}

This article is funded by "YUJIETalent Project of North China University of Technology".

\section{References}

[1] Fulgoni, Gian, Andrew Lipsman. Digital game changers: how social media will help usher in the era of mobile and multi-platform campaign-effectiveness measurement. Journal of Advertising Research, 
2014,54(1):11-16.

[2] Yongxi Li, Wei Wang, LinhuMo.Research on avoidance reaction mechanism of wechat circle of friends advertising.Chinese Culture Forum, 2016(09): 162-164.

[3] Si Fan, Yaobin Lu, Yingying Hu.Research on the influence of consistency and sociality on information flow advertising avoidance in social media environment.Journal of management, 2018,15(05): 759-766.

[4] Yun Wang, Xia Xiao, PinpinZheng, Abu Abdullah, Hua Fu. The application and development of protection motivation theory in individual behavior change.Health education in China, 2009, 25(11): $853-855+870$.

[5] Cai Liu, Qiang He, Yong Qin.Study on the willingness of rural adults to receive hepatitis B vaccine -Based on the theoretical model of protection motivation.Modern preventive medicine, 2015, 42(03): 448-450.

[6] Yoon C, Kim H. Understanding computer security behavioral intention in the workplace: An empirical study of Korean firms. Information Technology \& People, 2013, 26(4):425-456.

[7] Xiaojuan Zhang, Zhenzhen Li.An empirical study on the influencing factors of information security behavior intention of smart phone users.Information and Documentation Services, 2018(01): 74-80.

[8] Meng Yin, Qi Li.Research on the use of health app users based on the theory of protection motivation.Modern intelligence, 2016, 36(07): 63-70.

[9] Ifinedo P. Understanding information systems security policy compliance: An integration of the theory of planned behavior and the protection motivation theory. Computers \& Security, 2012, 31(1):83-95.

[10] Padayachee K. Taxonomy of compliant information security behavior. Computers \& Security, 2012, 31(5):673-680.

[11] Jie Zhen, ZongxiaoXie, Kanghong Li, Kunxiang Dong. Information security protection behavior of employees in Organizations: a multi case study based on the integration of PMT and FA.Management case study and review, 2017, 10(02): 114-130.

[12] Liming Yang, ZhiXu. A review of social media advertising effect: personalization, interactivity and advertising avoidance. The Press, 2016(21): 2-10.

[13] Celsi R L., and Olson J C.. The Role of Involvement in Attention and Comprehension Processes. Journal of Consumer Research, 1988, 15 (2): 210-224.

[14] Kim H., Huh J. Perceived Relevance and Privacy Concern Regarding Online Behavioral Advertising (OBA) and Their Role in Consumer Responses. Journal of Current Issues and Research in Advertising, 2017, 38(1):92-105.

[15] Zhu Y Q., Chang J H. The key role of relevance in personalized advertisement: Examining its impact on perceptions of privacy invasion, self-awareness, and continuous use intentions. Computers in Human Behavior, 2016, 65:442-447.

[16] Joanna Phillips, Stephanie M. Simply Captivating: Understanding Consumers' Attitudes Toward the Cinema as an Advertising Medium. Journal of Advertising, 2007, 36(1):81-94.

[17] Steven Bellman, AnikaSchweda, Duane Varan. The Residual Impact of Avoided Television Advertising. Journal of Advertising, 2010, 39(1):67-82.

[18] Siemens J C, Smith S, Dan F. Investigating the Effects of Active Control on Brand Recall Within In-Game Advertising. Journal of Interactive Advertising, 2015, 15(1):43-53.

[19] Ham C D. Exploring how consumers cope with online behavioral advertising. International Journal of Advertising, 2017, 36(4): 632-658.

[20] Ronald W Rogers. A Protection Motivation Theory of Fear Appeals and Attitude Change. Journal of Psychology Interdisciplinary \& Applied, 1975, 91(1):93-114.

[21] Lee D, Larose R, Rifon N. Keeping Our Network Safe: A Model of Online Protection Behavior. Behaviour\& Information Technology, 2008, 27(5):445-454.

[22] Liang H, Xue Y. Understanding Security Behaviors in Personal Computer Usage: A Threat Avoidance Perspective. Journal of the Association for Information Systems, 2010, 11(7):394-413.

[23] Baek TH, Morimoto M. Stay Away From Me. Journal of Advertising.Informa UK Limited; 2012 Apr;41(1):59-76.

[24] Floyd D., Prentice-Dunn S. and Rogers R. A Meta-analysis of Research on Protection Motivation ISSN: 0010-8189 
Theory. Journal of Applied Social Psychology, 2000, 30(2):407-429.

[25] Lwin M. O., Li B., Ang. R. P. Stop bugging me: An examination of adolescents' protection behavior against online harassment. Journal of Adolescence, 2012, 35(1):31-41.

[26] Mohamed N, Ahmad I H. Information privacy concerns, antecedents and privacy measure use in social networking sites: Evidence from Malaysia. Computers in Human Behavior, 2012, 28(6):2366-2375.

[27] Lee Y, Larsen K R. Threat or coping appraisal: determinants of SMB executives' decision to adopt anti-malware software. European Journal of Information Systems, 2009, 18(2):177-187.

[28] Nga N Ho-Dac, Stephen J Carson, William L Moore. The Effects of Positive and Negative Online Customer Reviews: Do Brand Strength and Category Maturity matter?. Journal of Marketing, 2013, 77(11):37-53.

[29] ZhiXu, Liming Yang. Research on user reception effect of WechatIn-Feed advertising. International Press, 2016, 38(05): 119-139.

[30] Cheikh-Ammar M, Barki H. "Like" is More than Just a Thumbs up: The Role of Feedback and Sociability in SNS Usage. Twentieth Americas Conference on Information Systems. 2014.

[31] Junglas I, Goel L, Abraham C, et al. The Social Component of Information Systems-How Sociability Contributes to Technology Acceptance. Journal of the Association for Information Systems, 2013, 14(10):585-616.

[32] Mittal V, Huppertz J W, Khare A. Customer complaining: the role of tie strength and information control. Journal of retailing, 2008, 84(2): 195-204.

[33] Aral S, Walker D. Tie strength, embeddedness, and social influence: A large-scale networked experiment. Management Science, 2014, 60(6): 1352-1370.

[34] Zijing Zhang. Suggestions on the development of WechatIn-Feed advertising communication. A Vast View on Publishing, 2018, 315(09): 66-68.

[35] Carr C T, Foreman A C. Identity shift III: Effects of publicness of feedback and relational closeness in computer-mediated communication. Media Psychology, 2016, 19(2): 334-358.

[36] Ha L, James E L. Interactivity reexamined: A baseline analysis of early business web sites. Journal of broadcasting \& electronic media, 1998, 42(4): 457-474.

[37] AkkınGürbüz H G, Demir T, GökalpÖzcan B, et al. Use of social network sites among depressed adolescents. Behaviour\& Information Technology, 2017, 36(5): 517-523.

[38] Zarouali B, Poels K, Walrave M, et al. 'You talking to me?'The influence of peer communication on adolescents' persuasion knowledge and attitude towards social advertisements. Behaviour\& Information Technology, 2018, 37(5): 502-516.

[39] Zhao, X., Lynch, J.G. \& Chen, Q., 2010. Reconsidering Baron and Kenny: Myths and Truths about Mediation Analysis. Journal of Consumer Research, 37(2), pp.197-206.

[40] Preacher, K.J. \& Hayes, A.F., 2004. SPSS and SAS procedures for estimating indirect effects in simple mediation models. Behavior Research Methods, Instruments, \& Computers, 36(4), pp.717-731.

[41] Hayes A. Introduction to mediation, moderation, and conditional process analysis. Journal of Educational Measurement, 2013, 51(3):335-337.

[42] Jung, A-Reum. The influence of perceived ad relevance on social media advertising: An empirical examination of a mediating role of privacy concern. Computers in Human Behavior, 2017, 70: 303-309.

[43] Dinev T., \& Hart P. Internet privacy concerns and their antecedents - Measurement validity and a regression model. Behavior and Information Technology, 2004, 23(6):413-422.

[44] Woon I., Tai G W. \& Low R A. Protection Motivation Theory approach to home wireless security. In Proceeding of 26th international conference on information systems, 2005.

[45] Crossler R. E. Protection motivation theory: understanding determinants to backing up personal data. In Proceedings of the 43rd Hawaii international conference on system sciences, 2010,1-10.

[46] Marett K, McNab A L, Harris R B. Social networking websites and posting personal information: An evaluation of protection motivation theory. AIS Transactions on Human-Computer Interaction, 2011, 3(3): 170-188.

[47] Larose R, Rifon N J. Promoting i- safety: effects of privacy warnings and privacy seals on risk assessment 
CONVERTER MAGAZINE

Volume 2021, No. 3

and online privacy behavior. Journal of Consumer Affairs, 2007, 41(1): 127-149.

[48] Kelly L, Kerr G, Drennan J. Avoidance of Advertising in Social Networking Sites. Journal of Interactive Advertising, 2010, 10(2):16-27.

ISSN: 0010-8189

(C) CONVERTER 2020

www.converter-magazine.info 